\title{
Social Networking Sites Acceptance: The Role of Personal Innovativeness in Information Technology
}

\author{
T. R. Wijesundara ${ }^{1,2} \&$ Sun Xixiang ${ }^{1}$ \\ ${ }^{1}$ School of Management, Wuhan University of Technology, Luoshi Road, Wuhan, PR China \\ ${ }^{2}$ Department of Marketing, University of Ruhuna, Matara, Sri Lanka \\ Correspondence: Sun Xixiang, School of Management, Wuhan University of Technology, Luoshi Road, Wuhan, \\ PR China. E-mail: 13971190718@163.com
}

Received: June 19, 2017

doi:10.5539/ijbm.v13n8p75
Accepted: June 2, $2018 \quad$ Online Published: June 30, 2018

URL: https://doi.org/10.5539/ijbm.v13n8p75

\begin{abstract}
Current wave of Social Networking Sites (SNS) has become a part of peoples' daily lives. This study investigates the role of Personal Innovativeness in Information Technology (PIIT), in acceptance of SNS. The theoretical perspective of Technological Acceptance Model (TAM) and PIIT were used to explain the relationships developed in the study. This research is descriptive in nature and is based on primary data collected through self-administered questionnaires, among a sample of 216 undergraduates in Sri Lanka. Findings reconfirmed the relationships in original TAM, enabling to use TAM in SNS context. Further, PIIT significantly predicts the Perceived Ease of Use (PEOU) of SNS. However, PIIT did not moderate the relationship between Perceived Usefulness (PU) and Intention to Use (IU) SNS. Theoretical and practical implications of these findings and directions for further research are discussed.
\end{abstract}

Keywords: Personal Innovativeness in Information Technology (PIIT), Social Networking Sites (SNS), Social Media, Facebook

\section{Introduction}

The recent revolution of Information Technology (IT) has diffused social media widely among the human beings. For instance, worldwide active Internet users are 3.773 billion and active social media users are 2.789 billion (Kemp, 2017). With the proliferation of social media, social science scholars are focusing their attention on understanding and explaining the new phenomenon. Besides, the business community is considering the application of social media for business purposes (Kaplan \& Haenlein, 2010).

Kaplan and Haenlein (2010) classified social media into following six categories. Blogs, collective projects (Wikipedia), Social Networking Sites (SNS) (Facebook), content communities (You Tube), virtual social worlds (Second Life) and virtual game worlds (Word of Warcraft). Current study focuses only one Social Networking Site (Facebook), in view of the fact that its popularity among researchers (Ellison, Steinfield, \& Lampe, 2007). Further, Facebook is the leading multilingual SNS (Grosseck, Bran, \& Tiru, 2011) which had daily average users of 1.37 billion as recorded in September 2017 (Facebook, 2017). In addition, it is the most famous SNS among the young Sri Lankans (Jayarathna \& Fernando, 2014) Both social media and SNS are used interchangeably in current study.

This study will employ Technology Acceptance Model (TAM), as the theoretical lens to find the determinants of SNS acceptance. TAM is one of the well researched models and was developed to predict, how individuals adopt and use new ITs. This model explains, Intention to Use (IU) IT depends on two beliefs: Perceived Usefulness (PU) and Perceived Ease Of Use (PEOU) (Venkatesh \& Bala, 2008). Since, SNS is a novel technology, scholars have used TAM to explain the acceptance of SNS by individuals (Acarli \& Sağlam, 2015; Choi \& Chung, 2013; Rauniar, Rawski, Yang, \& Johnson, 2014). Users will consider how easy it is to use social media and to what extent it supports to achieve their social-media-related needs when accepting a social media site (Rauniar et al., 2014).

Consumer innovativeness plays a significant role in accepting Internet based new technologies (Aldas-Manzano, Lassala-Navarre, Ruiz-Mafe, \& Sanz-Blas, 2009; Ratten, 2014). Momentous body of research on SNS acceptance has gathered evidence to support the importance of PEOU and PU (Choi \& Chung, 2013; Pinho \& 
Soares, 2011; Qin, Kim, Hsu, \& Tan, 2011; Rauniar et al., 2014). However, very little work has been done to understand the role of Personal Innovativeness in Information Technology (PIIT) on SNS acceptance. Agarwal and Prasad (1998, p. 206) defined PIIT as "the willingness of an individual to try out any new information technology". Social media is one of the most powerful innovative media in the era (Lee \& Ma, 2012) and PIIT is a significant antecedent in accepting innovative technologies (Jeong, Yoo, \& Heo, 2009; Joo, Lee, \& Ham, 2014). Thus, having the faculty of reasons that there should be a considerable impact of PIIT on SNS acceptance formulates a matter of worth exploring. As such, current study incorporates PIIT to the TAM as a determinant of SNS acceptance.

Findings of this study contribute to both academia and industry in understanding the SNS acceptance. Firstly, it will fill the gap in existing social media literature by considering PIIT as a determinant for SNS acceptance. Next, most SNS related studies are grounded in developed country context. Current study provides empirical evidence for SNS acceptance from Sri Lanka, which is a lower middle- income country with a population of 20.9 million (World Bank, 2016). However, according to the Networked Readiness Index 2016, Sri Lanka is the leading country with the world rank of 63 in the South Asian region. There were 5.5 million Facebook subscribes in December / 2017 and its penetration was 26.3 \% (Internet World Stats, 2017). These facts provide evidence to consider, Sri Lanka as a feasible research context for SNS studies. Secondly, from the industry perspective, findings encourage both SNS companies as well as marketers to consider PIIT as a valuable factor in designing firm strategies.

This study attempts to extend the TAM by including PIIT as a predictor for SNS acceptance and the rest of the paper is arranged as follows. First part is composed for development of the conceptual framework by emphasizing the relationships among the constructs. Then the methodology discusses the methods employed in the study with the rationale for each selected method. Following methodology, results are presented in an orderly sequence to answer the study questions. Discussion section will compare the findings with previous studies. Finally, conclusion is presented with the managerial implications and directions for future research.

\section{Theory, Hypothesis Development and Conceptual Framework}

\subsection{Social Networking Sites}

SNS are "Web-based services that allow individuals to (1) construct a public or semi-public profile within a bounded system, (2) articulate a list of other users with whom they share a connection, and (3) view and traverse their list of connections and those made by others within the system"(Boyd \& Ellison, 2007). According to Kim, Jeong, and Lee (2010, p. 216) SNS are "Web sites that make it possible for people to form online communities, and share user-created contents". Further, it can be identified as "online communities that focus on bringing together people with similar interests or who are interested in exploring the interests and activities of others" (Marcus \& Krishnamurthi, 2009, p. 59).These online networks have different objectives such as friendship-oriented SNSs (Facebook) and professional-oriented SNSs (LinkedIn) (Shneor \& Efrat, 2014).

\subsection{Technology Acceptance Model}

There are a number of theoretical models used by scholars to study user acceptance and usage behavior of new technologies. However, TAM is the most widely applied model (Venkatesh, 2000) and it is a valuable instrument for predicting intention to use information system (Szajna, 1996). TAM was developed by Davis (1986) based on the theoretical foundation of the Theory of Reasoned Action (TRA) (Fishbein \& Ajzen, 1975). TRA explains general human behavior while, TAM particularly explains the determinants of computer acceptance (Davis, Bagozzi \& Warshaw, 1989). TRA suggests that beliefs influence attitudes, which in turn leads to intentions and finally determine behaviors. According to TAM, PEOU and PU are the basic antecedents for developing attitudes toward technology, Behavioral Intention (BI) and finally Actual Usage (AU) of the technology (Davis, 1986). PEOU refers to "the degree to which a person believes that using a particular system would be free of effort (Davis, 1989, p.320) and PU is defined as "the degree to which a person believes that using a particular system would enhance his or her job performance (Davis, 1989, p.320).

Later, the model was revised and Venkatesh and Davis (1996) analyzed the antecedents of PEOU, without the attitudes (Rondan-Cataluña, Arenas-Gaitán, \& Ramírez-Correa, 2015). Over the time, the TAM model has been changed twice as the so-called TAM2 (Venkatesh \& Davis, 2000) and TAM 3 (Venkatesh \& Bala, 2008). TAM 2 includes social influence processes and cognitive instrumental processes (Rondan-Cataluña et al., 2015) and TAM 3 came up with antecedents of PEOU.

Rauniar et al. (2014) have modified the TAM to explain the acceptance of social media technology and came up with a new model called revised TAM. The revised TAM includes more constructs relevant to social media 
acceptance (critical mass, capability, perceived playfulness and trustworthiness).

\subsection{TAM and SNS Acceptance}

In order to be compatible with SNS context, general definitions given to constructs in original TAM change as follows. PEOU is the "degree to which the social media site is free of effort" (Rauniar et al., 2014, p. 11) and PU is the "extent to which the social media user believes that using a particular social media site helps to meet the related goal-driven needs of the individual" (Rauniar et al., 2014, p. 10).

PEOU is a leading antecedent in explaining PU of personal computers (Igbaria, Zinatelli, Cragg, \& Cavaye, 1997). Liu (2010) added empirical evidence to prove the positive relationship between PEOU and PU in wikis usage. The higher the consumer PEOU, the greater the PU of SNS (Pinho \& Soares, 2011). According to Qin et al. (2011) PEOU has a significant positive influence on the PU of SNS. As per Choi and Chung (2013) PEOU is a fundamental determinant to PU of SNS. Further, Rauniar et al. (2014) concluded that there is a positive relationship between PEOU and PU of social media site.

Current study considers IU as the "continued intention to perform social media-related activities using the social media site" (Rauniar et al., 2014, p. 14) and AU as the frequency of social media usage. PU is the key predictor of user's IU computers (Davis et al., 1989) and wikis (Liu, 2010). Qin et al. (2011) suggest a positive relationship between PU and IU SNS. Further, Choi and Chung (2013) mentioned that PU has robust effects on IU SNS. Moreover, Rauniar et al. (2014) provided sufficient evidence to prove the positive relationship between PU and IU social media sites.

IU wiki has a significant direct impact on actual wiki usage (Liu, 2010) and according to Rauniar et al. (2014) IU social media is positively related with actual social media usage.

Upon the theoretical foundation of TAM and prior empirical evidence, this study proposes the following three hypotheses for SNS acceptance.

\section{H1: PEOU of SNS is positively related to PU of SNS}

H2: PU of SNS is positively related to IU the SNS

H3: IU of SNS is positively related with the AU of SNS

\subsection{Personal Innovativeness and Social Networking Sites Acceptance}

PIIT is a vital concept for understanding the acceptance of information technology. It can be defined as the "tendency to be a technology pioneer and thought leader" (Parasuraman, 2000, p. 311). As per Schillewaert, Ahearne, Frambach, and Moenaert $(2005$, p. 326) it is "predisposition or attitude describing a person's learned and enduring cognitive evaluations, emotional feelings and action tendencies towards adopting new information technologies". Based on the previous definitions, willingness of users to try SNS as a new media will be considered as "PIIT" in this study.

Schillewaert et al. (2005) mentioned that PIIT is positively related with PEOU of sales automation system. According to $\mathrm{Lu}$, Yao, and $\mathrm{Yu}$ (2005) PIIT predicts the perceived ease of wireless Internet services. van Raaij and Schepers (2008), prove the same relationship with e-learning system. Some recent studies (Joo et al., 2014; Koivisto, Makkonen, Frank, \& Riekkinen, 2016) further provide empirical evidence to support the impact of personal innovativeness on PEOU of the technology.

Moderating effect evokes when third construct alter the existing relationship between two related constructs (Baron \& Kenny, 1986). Jeong et al. (2009) assert that PIIT has a moderating effect in the relationship between perceived need and purchase intention of mobile-RFID services. Agarwal and Prasad (1998) mentioned PIIT plays the role of moderator in the technology usage.

It was noticed that very few endeavors were considered to understand the impact of PIIT on SNS acceptance. Since SNS is a new technology, previous studies relating to other technologies were refered to build following hypotheses. Thus, the hypotheses underpinning the current study are that:

H4:PIIT is positively related to PEOU of SNS

H5: PIIT has a moderation effect between PU and IU SNS 


\subsection{Conceptual Framework}

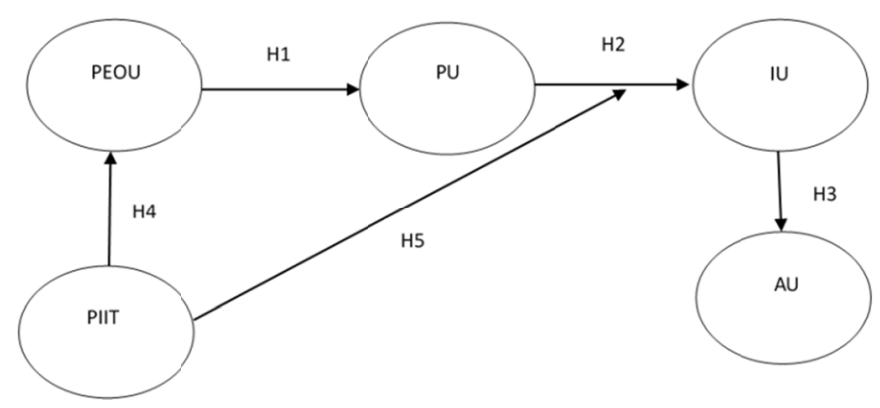

Key: PEOU- Perceiver Ease Of Use;

PU- Perceived Usefulness;

IU- Intention to Use;

AU- Actual Usage;

PIIT - Personal Innovativeness in Information Technology

\section{Methodology}

\subsection{Participants and Data Collection}

A survey was conducted to gather data, for testing the developed hypotheses in the study. Full time undergraduates from one state university were employed as respondents. Based on previous studies Shaouf, Lü, and $\mathrm{Li}$ (2016) pointed out that university students might be the most suitable sample for e-commerce related studies given that they have an opportunity to use Internet for communication and commercial matters. Social media usage is also an online activity, which relates to communication purpose. In addition, majority of the Sri Lankan SNS users are in the age group of 18 to 34 (Amarasinghe, 2011) which can be represented by undergraduates.

Self - Administered paper-based questionnaire, comprised of closed ended questions, was used as the data collection tool. The questionnaire is an "efficient data collection mechanism when researcher knows exactly what is required and how to measure the variables of interest" (Sekaran, 1992, p. 200). First section consisted of questions to measure the main constructs with Likert type scale. Next part of the questionnaire included personal and background information. Table 1 summarizes the sample description.

The questionnaire was pilot-tested on 12 respondents to test the reliability and validity of the measurement items since they were adopted from previous studies. It was discovered that all the scales were suitable for further proceeding. After employing simple random sampling method, 400 questionnaires were distributed among the students in the lecture rooms and they were requested to submit the completed questionnaires on the following day. However, only 251 questionnaires were submitted and 35 were dropped due to the incomplete answers. Finally, 216 questionnaires were used in the analysis resulting in a response rate of 54\% (216/400). 
Table 1. Sample description

\begin{tabular}{|c|c|c|}
\hline Demographic Factor & Category & Percentage \\
\hline \multirow[t]{2}{*}{ Gender } & Male & 42.4 \\
\hline & Female & 57.7 \\
\hline \multirow[t]{4}{*}{ Academic Year } & $1^{\text {st }}$ year & 4.2 \\
\hline & $2^{\text {nd }}$ year & 36.6 \\
\hline & $3^{\text {rd }}$ year & 47.2 \\
\hline & Final year & 12 \\
\hline \multirow[t]{4}{*}{ Internet Usage per day } & Less than 1 hour & 46.3 \\
\hline & 1-3 hours & 40.3 \\
\hline & $3-6$ hours & 8.3 \\
\hline & More than 6 hours & 5.1 \\
\hline \multirow[t]{3}{*}{ Experience with Social Media } & Less than one year & 15.3 \\
\hline & $1-3$ years & 33.3 \\
\hline & More than 3 years & 51.4 \\
\hline \multirow[t]{5}{*}{ Social Media Friends } & Less than 50 & 8.8 \\
\hline & $51-100$ & 10.6 \\
\hline & $101-250$ & 25.5 \\
\hline & $251-500$ & 20.8 \\
\hline & More than 500 & 34.1 \\
\hline \multirow[t]{5}{*}{ Social Media Usage per week } & $0-2$ hours & 35.6 \\
\hline & $2-4$ hours & 24.2 \\
\hline & 4-6 hours & 18.5 \\
\hline & $6-8$ hours & 6.9 \\
\hline & More than 8 hours & 14.8 \\
\hline
\end{tabular}

\subsection{Measures}

Measurement scales used in the current study were adopted from past studies, including PEOU (Rauniar et al., 2014) PU (Choi \& Chung, 2013; Rauniar et al., 2014), IU (Choi \& Chung, 2013), PIIT (Agarwal \& Prasad, 1998) and AU (Rauniar et al., 2014). Except for AU, (single item) all other latent variables in the research include multiple items. AU was measured by the frequency of SNS usage (never, rarely, occasionally, often, and frequently). Five points Likert type scale was used to measure other latent variables, where respondents had to make their level of agreement for given statements from strongly agree to strongly disagree.

\section{Results}

\subsection{Validity and Reliability}

Content validity, which refers to the "degree to which elements of an assessment instrument are relevant to and representative for the target construct for a particular assessment purpose" (Haynes, Richard, \& Kubany, 1995, p. 238) was assured by allowing other researchers and industry experts to test the questionnaire. They were requested to highlight the possible ambiguity in the questions. Based on their recommendations, slight alterations were made to the questionnaire prior to the pilot survey.

Partial Least Squares Structural Equation Modeling (PLS-SEM) was used with Smart PLS 3 software to test hypothesis and estimate path models involving latent variables. Identification problems may not occur with PLS when it attempts to test structural model with single item measures (Hair, Black, Babin \& Anderson, 2009). This study includes a single item construct (AU), which is one of the endogenous constructs in the proposed model. Further, PLS allows to test the reliability and validity from different perspectives (Bugshan, 2015) and Smart PLS is one of the prominent software for PLS-SEM (Wong, 2013). Reliability and construct validity were ensured by Cronbach's alpha, composite reliability (CR), factor analysis, and average variance extracted (AVE). Coefficient alpha is the widely used reliability coefficient in social-science research (Green, 2003). As per Table 2 , all Cronbach's alpha values were above 0.7 for all constructs indicating sufficient internal consistency (Gliem \& Gliem, 2003). Furthermore, composite reliabilities of the constructs were higher than 0.7, which is the satisfactory level as proposed by Hair, Ringle, and Sarstedt (2011). 
Table 2. Properties of measurement construct

\begin{tabular}{|c|c|c|c|c|c|c|c|c|}
\hline $\begin{array}{l}\text { Constr } \\
\text { uct }\end{array}$ & Items & Measurement Variables & Loadings & Mean & SD & AVE & $\mathrm{CR}$ & A \\
\hline \multirow[t]{4}{*}{ PEOU } & & & & 3.45 & 0.67 & 0.562 & 0.793 & 0.716 \\
\hline & PEOU1 & Facebook is flexible to interact with & 0.793 & & & & & \\
\hline & PEOU 2 & I find it easy to get Face book to do what I want to do & 0.745 & & & & & \\
\hline & PEOU 4 & I find Facebook easy to use & 0.708 & & & & & \\
\hline \multirow[t]{4}{*}{ PU } & & & & 3.50 & 0.66 & 0.551 & 0.786 & 0.794 \\
\hline & PU2 & I find Facebook useful in my personal life & 0.772 & & & & & \\
\hline & PU3 & $\begin{array}{l}\text { Using Facebook enhances my effectiveness to stay in touch with } \\
\text { others }\end{array}$ & 0.695 & & & & & \\
\hline & PU4 & $\begin{array}{l}\text { Using Facebook makes it easier to stay informed with my friends } \\
\text { and family }\end{array}$ & 0.757 & & & & & \\
\hline \multirow[t]{4}{*}{ IU } & & & & 3.32 & 0.76 & 0.570 & 0.797 & 0.729 \\
\hline & IU1 & I will continue to use Facebook in the future & 0.875 & & & & & \\
\hline & IU2 & I will continue to increase my use of Facebook & 0.730 & & & & & \\
\hline & IU3 & I will continue to use Facebook whenever possible & 0.642 & & & & & \\
\hline \multirow[t]{4}{*}{ PIIT } & & & & 3.38 & 0.70 & 0.605 & 0.820 & 0.795 \\
\hline & PIIT1 & $\begin{array}{l}\text { If I heard about a new information technology, I would look for } \\
\text { ways to experiment with it }\end{array}$ & 0.856 & & & & & \\
\hline & PIIT2 & $\begin{array}{l}\text { Among my peers, I am usually the first to try out new information } \\
\text { technologies }\end{array}$ & 0.69 & & & & & \\
\hline & PIIT4 & I like to experiment with new information technologies & 0.779 & & & & & \\
\hline $\mathrm{AU}$ & AU1 & $\begin{array}{l}\text { How often per week do you visit your Facebook account((single } \\
\text { item) (Never, rarely, occasionally, often, frequently) }\end{array}$ & & 3.03 & 1.71 & & & \\
\hline
\end{tabular}

Note. All items (without AU) shared a common prompt: "Indicate how much you agree with each option by marking the appropriate response" and were measured with a 5-point Likert-type scale ranging from "Strongly Disagree" to "Strongly Agree."

Convergent and discriminate validity were ensured by factor analysis (SPSS 22) since it is the widely used method for this purpose. To measure the sample adequacy for factor analysis Kaiser-Meyer-Olkin (KMO) value is used. In current study, KMO value was 0.815, which is at a satisfactory level (Dziuban \& Shirkey, 1974), and Bartlett's Test of Sphericity was found to be significant. It ascertains that the data were generally appropriate for factor analysis. Table 2 shows that all factor loadings are at a higher level and the lowest value was 0.642 which is higher than satisfactory level (Hair et al., 2009). Further, AVE for all constructs were higher than 0.5 (Table 2) which is the minimum level recommended by Fornell and Larcker (1981).

\subsection{Hypotheses Test}

Standardized parameters for the research model were obtained by bootstrap simulation (Wong, 2013) (Table 3). The results from the PLS t-Values confirmed the significance of first four hypotheses and fifth hypothesis was not significant since t value was smaller than 1.96(Wong, 2013). The first hypothesis suggested that there is a positive relationship between PEOU and PU. The Path coefficient of 0.501 was found to be statistically significant. Second hypothesis was PU of SNS is positively related to IU the SNS, was supported by empirical evidence ( $\beta .401)$. Both third and fourth hypotheses were supported with standardized coefficient values of 0.192 and 0.254 , respectively. As per the analysis, fifth hypothesis, which suggested a moderation effect of PIIT, was rejected since path coefficient was not statistically significant at $0.05 \%(\beta 0.225) . R^{2}$ values of $0.75,0.50$, or 0.25 for endogenous latent variables can be considered as substantial, moderate, or weak, respectively. However, $R^{2}$ results of 0.20 are considered high in some study disciplines, for instance in consumer behavior (Hair et al., 2011 p.145). Given that current study is about user behavior in social media context, the results indicate that model explains a large part of the variance in the endogenous variables PEOU,PU, IU, AU with an $\mathrm{R}^{2}$ of 0.161 , $0.190,0.188$ and 0.198 respectively (Figure 2 ). 
Table 3. Summary of hypotheses testing results

\begin{tabular}{|c|c|c|c|c|}
\hline Relationship & Hypotheses & $\mathrm{t}-\mathrm{V}$ alue & Path coefficients & Conclusion \\
\hline $\mathrm{PEOU} \rightarrow \mathrm{PU}$ & H1 & $8.944^{*}$ & 0.501 & Supported \\
\hline $\mathrm{PU} \rightarrow \mathrm{IU}$ & $\mathrm{H} 2$ & $6.691 *$ & 0.401 & Supported \\
\hline $\mathrm{IU} \rightarrow \mathrm{AU}$ & $\mathrm{H} 3$ & $2.927^{*}$ & 0.192 & Supported \\
\hline $\mathrm{PIIT} \rightarrow \mathrm{PEOU}$ & $\mathrm{H} 4$ & $3.060 *$ & 0.254 & Supported \\
\hline $\begin{array}{l}\text { Moderating effect of } \\
\text { PIIT }\end{array}$ & $\mathrm{H} 5$ & 1.456 & 0.225 & Not Supported \\
\hline
\end{tabular}

* Significant at $5 \%$ for the two-tailed test $(>1.96)$.

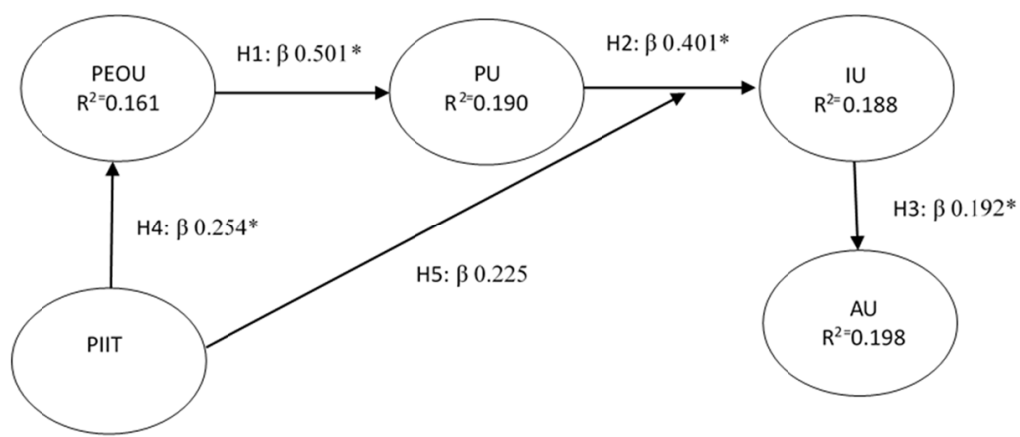

Figure 2. Final structural model

Key: PEOU- Perceiver Ease Of Use

PU- Perceived Usefulness;

IU- Intention to Use;

AU- Actual Usage;

PIIT - Personal Innovativeness in Information Technology.

\section{Discussion}

This research examines the role of PIIT in acceptance of SNS among Sri Lankan undergraduates. As explained, the TAM by itself may not be adequate in explaining the SNS acceptance. Revised TAM for social media developed by Rauniar et al. (2014) has not considered PIIT despite the fact that it is an essential human feature in accepting new technology. As such, this study incorporates PIIT to the TAM as a determinant of SNS usage.

Study provides sufficient evidence to support first three hypotheses in SNS context, and confirm the original TAM relationships and other previous findings with different technologies. The first hypothesis which assumes, a positive relationship between PEOU of SNS and PU of SNS has proved by empirical evidence, supporting Rauniar et al. (2014), Liu (2010), Phno and Soares (2011), Qin et al., (2011). Then a positive relationship between PU of SNS and IU SNS was assumed. There was sufficient evidence to accept this hypothesis supporting Rauniar et al., (2014) in a developing country context. Further, this finding is in agreement with previous scholars (Davis et., al 1989, Liu, 2010, Choi \& Chung 2013). The third hypothesis, that there is a positive relationship between IU and AU of SNS, was supported. This finding is compatible with Rauniar et al. (2014) and Liu (2010).

Hypothesis four, which was originally incorporated in the current study, was proved indicating PIIT is a significant factor in predicting PEOU of SNS. Finding is in agreement with Joo et al. (2014), Koivisto et al. (2016), Lu et al. (2005), Schillewaert et al. (2005) and van Raaij and Schepers (2008). Even though, technology is easy to use, individuals might still consider traditional technologies when user innovativeness is low. This may be the reason for positive relationship between PIIT and PEOU of SNS.

However, moderation effect of PIIT, which was mentioned in the fifth hypothesis, was rejected, since there was no sufficient evidence. Finding is not concurring with Jeong et al. (2009). This can be due to two main reasons. Firstly Jeong et al., (2009) considered PU with intension to purchase mobile-RFID services. However, intention to purchase is coupled with financial cost. Therefore, individuals with a higher personal innovativeness may not consider buying new technology at once although they perceive the technology as useful. Instead, they might search for other advanced technologies to fulfill the same requirement. As such, PIIT can moderate the relationship between PU and intention to purchase the technology. Conversely, current study considers PU with 
intention to use. Since SNS usage is devoid of a financial cost, individuals may use SNS without any hesitation.

Secondly, it may be due to the cultural reasons. Thatcher, Stepina, Srite, and Liu (2003) suggested that there is a relationship between PIIT and uncertainty avoidance aspect of the culture. Jeong et al. (2009) provided evidence from South Korea, to support the moderation effect of PIIT. South Korea is one of the most high uncertainty avoidance cultures in the world (85 Marks) (Hofstede, 2016). Comparatively, Sri Lanka is a low uncertainty avoidance culture (45 Marks) (Hofstede, 2016).

\section{Conclusion}

Based on empirical evidence, current study contributes to the development of social media literature in the area of SNS acceptance. From a practitioner's standpoint, study provides useful insight for SNS companies as well as practical marketers about SNS acceptance and its determinants. Findings support original TAM relationship and allow considering SNS acceptance from consumer innovativeness perspective.

This is the first study, which considers PIIT as a determinant for SNS acceptance through adopting scales from existing literature. Indicators were validated through proper validity and reliability techniques providing an opportunity to replicate them in future SNS studies. This is a significant contribution to the social media theory. Results reconfirmed relationship in original TAM ( $\mathrm{H} 1, \mathrm{H} 2$, and $\mathrm{H} 3)$ enabling to use TAM in SNS context. Further, it was found in current study that PIIT is significant in predicting PEOU of SNS. Previous scholars have proved this relationship with various technologies such as internet services, e-learning system. However, SNS researchers had not considered the importance of personal innovativeness in accepting SNS. Current study filled this gap by providing empirical evidence to support the importance of personal innovativeness from developing country context. This is also a significant contribution to the social media literature since most previous studies are based on developed countries. Apart from that, empirical evidence proved that personal innovativeness is not a moderating factor in SNS context. However, personal innovativeness had a moderating effect on other technologies such as WWW and mobile-RFID services. This study indicates that the role of personal innovativeness might vary with different technologies.

Findings of this study will allow both SNS companies as well as marketers to consider PIIT as a valuable aspect in designing organization strategies. Advertising income is the main revenue source of many SNS companies. On the other hand, advertising rates depend on the coverage (number of users) of the particular SNS. Therefore, the number of users is an important criterion for success of SNS. With the proliferation of social media concept, now most companies are entering into the SNS business. It is of paramount importance to have a clear idea about the factors influencing on SNS acceptance in order to attract more users. This study proves that not only PEOU and PU but also PIIT is significant in accepting SNS. As such, strategies of these companies should be focused to attract low PIIT individuals as well as increase usage frequency of these individuals. This could be achieved by including more user friendly and entertaining features. Further, SNS companies should communicate with low PIIT individuals to emphasize the importance of a particular site. Company might fail to spot the low innovative potential users who rely on traditional media (newspaper, magazine) if they select digital media to advertise SNS (eg. SNS advertisement in gossip web site). Therefore, when developing media strategies, it might be beneficial for SNS companies to consider both online and offline methods.

With the proliferation of SNS, now most marketers use SNS as the communication medium. SNS may not be a good platform for low-tech products, which are used by less innovative individuals. These individuals might not use SNS or usage frequency could be low. Hence, SNS advertising campaign may not be effective for this target market and thus companies should consider offline media.

Though, the findings include valuable insights about SNS acceptance, there are some limitations. There are many SNS such as LinkedIn, Twitter, we chat and Facebook. However, in this study only Facebook was selected. In order to get deeper knowledge about SNS, it may be better to study this model with other SNS. Another limitation is that, only young adults were recruited for current study. However, other demographic groups are also growing fast. Future studies should take into account more age groups since age can be an important factor in accepting SNS. Finally, it is important for future studies to focus on understanding the impact of personal innovativeness for different technologies.

\section{Reference}

Acarli, D. S., \& Sağlam, Y. (2015). Investigation of Pre-service Teachers' Intentions to Use of Social Media in Teaching Activities within the Framework of Technology Acceptance Model. Procedia-Social and Behavioral Sciences, 176, 709-713. https://doi.org/10.1016/j.sbspro.2015.01.530 
Agarwal, R., \& Prasad, J. (1998). A conceptual and operational definition of personal innovativeness in the domain of information technology. Information systems research, 9(2), 204-215. https://doi.org/10.1287/isre.9.2.204

Aldas-Manzano, J., Lassala-Navarre, C., Ruiz-Mafe, C., \& Sanz-Blas, S. (2009). The role of consumer innovativeness and perceived risk in online banking usage. International Journal of Bank Marketing, 27(1), 53-75. https://dx.doi.org/10.1108/02652320910928245

Amarasinghe, A. (2011). Sri Lanka Reaches 1 Million Users on Facebook. Retrieved from http://www.amisampath.com/2011/07/sri-lanka-reaches-1-million-users-on.html

Baron, R. M., \& Kenny, D. A. (1986). The moderator-mediator variable distinction in social psychological research: Conceptual, strategic, and statistical considerations. Journal of Personality and Social Psychology, 51(6), 1173. https://doi.org/10.1037/0022-

Boyd, D. M., \& Ellison, N. B. (2007). Social network sites: Definition, history, and scholarship. Journal of Computer-Mediated Communication, 13(1), 210-230. https://doi.org/10.1111/j.1083-6101.2007.00393.x

Bugshan, H. (2015). Open innovation using Web 2.0 technologies. Journal of Enterprise Information Management, 28(4), 595-607. https://doi.org/10.1108/JEIM-09-2014-099

Choi, G., \& Chung, H. (2013). Applying the Technology Acceptance Model to Social Networking Sites (SNS): Impact of Subjective Norm and Social Capital on the Acceptance of SNS. International Journal of Human-Computer Interaction, 29(10), 619-628. https://doi.org/10.1080/10447318.2012.756333

Davis , F. D. (1986). A technology acceptance model for empirically testing new end-user information systems: Theory and results. Massachusetts Institute of Technology. Retrieved from https://www.researchgate.net/profile/Fred_Davis2/publication/35465050A_technology_acceptance_model for_empirically_testing_new_enduser_information_systems_theory_and_results_/links/0c960519f $\overline{\mathrm{fbaddf}} 3 \overline{\mathrm{b}}$ a7000000.pdf

Davis, F. D. (1989). Perceived usefulness, perceived ease of use, and user acceptance of information technology. MIS quarterly, 319-340. https://doi.org/10.2307/249008

Davis, F. D., Bagozzi, R. P., \& Warshaw, P. R. (1989). User acceptance of computer technology: a comparison of two theoretical models. Management Science, 35(8), 982-1003. https://doi.org/10.1287/mnsc.35.8.982

Dziuban, C. D., \& Shirkey, E. C. (1974). When is a correlation matrix appropriate for factor analysis? Some decision rules. Psychological Bulletin, 81(6), 358. https://doi.org/10.1037/h0036316

Ellison, N. B., Steinfield, C., \& Lampe, C. (2007). The benefits of Facebook "friends:" Social capital and college students' use of online social network sites. Journal of Computer-Mediated Communication, 12(4), 1143-1168. https://doi.org/10.1111/j.1083-6101.2007.00367.x

Facebook. (2016). Facebook Reports Third Quarter 2016 Results. Retrieved January 20, 2018, from https://investor.fb.com/investor-news/press-release-details/2017/Facebook-Reports-Third-Quarter-2017-Res ults/default.aspx

Fishbein, M., \& Ajzen, I. (1975). Belief, attitude, intention and behavior: An introduction to theory and research.

Fornell, C., \& Larcker, D. F. (1981). Structural equation models with unobservable variables and measurement error: Algebra and statistics. Journal of Marketing Research, 382-388. https://doi.org/10.2307/3150980

Gliem, R. R., \& Gliem, J. A. (2003). Calculating, interpreting, and reporting Cronbach's alpha reliability coefficient for Likert-type scales.

Green, S. B. (2003). A coefficient alpha for test-retest data. Psychological Methods, 8(1), 88. https://dx.doi.org/10.1037/1082-989X.8.1.88

Grosseck, G., Bran, R., \& Tiru, L. (2011). Dear teacher, what should I write on my wall? A case study on academic uses of Facebook. Procedia-Social and Behavioral Sciences, 15, 1425-1430. https://doi.org/10.1016/j.sbspro.2011.03.306

Hair, J. F., Black, W. C., Babin, B. J., \& Anderson, R. E. (2009). Multivariate Data Analysis (7th ed.). Pearson Prentice Hall.

Hair, J. F., Ringle, C. M., \& Sarstedt, M. (2011). PLS-SEM: Indeed a silver bullet. Journal of Marketing theory and Practice, 19(2), 139-152. 
Haynes, S. N., Richard, D., \& Kubany, E. S. (1995). Content validity in psychological assessment: A functional approach to concepts and methods. Psychological Assessment, 7(3), 238. https://doi.org/10.1037/1040-3590.7.3.238

Hofstede, G. (2016). South Korea. Retrieved November 25, 2016, from https://geert-hofstede.com/south-korea.html

Hofstede, G. (2016). Sri Lanka. Retrieved November 10, 2016, from https://geert-hofstede.com/sri_lanka.html

Igbaria, M., Zinatelli, N., Cragg, P., \& Cavaye, A. L. (1997). Personal computing acceptance factors in small firms: a structural equation model. MIS Quarterly, 279-305. https://doi.org/10.2307/249498

Internet World Stats. (2017). Asia Marketing Research, Internet Usage, Population Statistics and Facebook Information. Retrieved March 10, 2018, from http://www.internetworldstats.com/asia.htm\#lk

Jayarathna, L., \& Fernando, W. (2014). Relationship between Facebook Usage and the Student Engagement of Sri Lankan Management Undergraduates. World Academy of Science, Engineering and Technology, International Journal of Social, Behavioral, Educational, Economic, Business and Industrial Engineering, 8(8), 2689-2693.

Jeong, N., Yoo, Y., \& Heo, T. Y. (2009). Moderating effect of personal innovativeness on mobile-RFID services: Based on Warshaw's purchase intention model. Technological Forecasting and Social Change, 76(1), 154-164. https://doi.org/10.1016/j.techfore.2008.08.007

Joo, Y. J., Lee, H. W., \& Ham, Y. (2014). Integrating user interface and personal innovativeness into the TAM for mobile learning in Cyber University. Journal of Computing in Higher Education, 26(2), 143-158. https://doi.org/10.1007/s12528-014-9081-2

Kaplan, A. M., \& Haenlein, M. (2010). Users of the world, unite! The challenges and opportunities of Social Media. Business horizons, 53(1), 59-68. https://doi.org/10.1016/j.bushor.2009.09.003

Kemp, S. (2017). Digital in 2017. Global Overview. Retrieved January 17, 2018, from https://wearesocial.com/uk/special-reports/digital-in-2017-global-overview

Kim, W., Jeong, O.-R., \& Lee, S.-W. (2010). On social Web sites. Information Systems, 35(2), 215-236. https://doi.org/10.1016/j.is.2009.08.003

Koivisto, K., Makkonen, M., Frank, L., \& Riekkinen, J. (2016). Extending the Technology Acceptance Model with Personal Innovativeness and Technology Readiness: A Comparison of Three Models. Paper presented at the BLED 2016.

Lee, C. S., \& Ma, L. (2012). News sharing in social media: The effect of gratifications and prior experience. Computers in Human Behavior, 28(2), 331-339. https://doi.org/10.1016/j.chb.2011.10.002

Liu, X. (2010). Empirical testing of a theoretical extension of the technology acceptance model: An exploratory study of educational wikis. Communication Education, 59(1), 52-69. https://doi.org/10.1080/03634520903431745

Lu, J., Yao, J. E., \& Yu, C.-S. (2005). Personal innovativeness, social influences and adoption of wireless Internet services via mobile technology. The Journal of Strategic Information Systems, 14(3), 245-268. https://dx.doi.org/10.1016/j.jsis.2005.07.003

Marcus, A., \& Krishnamurthi, N. (2009). Cross-cultural analysis of social network services in Japan, Korea, and the USA Internationalization, design and global development (pp. 59-68): Springer.

Networked Readiness Index. (2016). Retrieved November 10, 2016, from https://widgets.weforum.org/gitr2015/

Parasuraman, A. (2000). Technology Readiness Index (TRI) a multiple-item scale to measure readiness to embrace new technologies. Journal of service research, 2(4), 307-320. https://doi.org/10.1177/109467050024001

Pinho, J. C. M. R., \& Soares, A. M. (2011). Examining the technology acceptance model in the adoption of social networks. Journal of Research in Interactive Marketing, 5(2/3), 116-129. https://dx.doi.org/10.1108/17505931111187767

Qin, L., Kim, Y., Hsu, J., \& Tan, X. (2011). The effects of social influence on user acceptance of online social networks. International Journal of Human-Computer Interaction, 27(9), 885-899. https://dx.doi.org/10.1080/10447318.2011.555311 
Ratten, V. (2014). A US-China comparative study of cloud computing adoption behavior: The role of consumer innovativeness, performance expectations and social influence. Journal of Entrepreneurship in Emerging Economies, 6(1), 53-71. https://dx.doi.org/10.1108/JEEE-07-2013-0019

Rauniar, R., Rawski, G., Yang, J., \& Johnson, B. (2014). Technology acceptance model (TAM) and social media usage: an empirical study on Facebook. Journal of Enterprise Information Management, 27(1), 6-30. https://dx.doi.org/10.1108/JEIM-04-2012-0011

Rondan-Cataluña, F. J., Arenas-Gaitán, J., \& Ramírez-Correa, P. E. (2015). A comparison of the different versions of popular technology acceptance models: A non-linear perspective. Kybernetes, 44(5), 788-805. https://dx.doi.org/10.1108/K-09-2014-0184

Schillewaert, N., Ahearne, M. J., Frambach, R. T., \& Moenaert, R. K. (2005). The adoption of information technology in the sales force. Industrial Marketing Management, 34(4), 323-336. https://dx.doi.org/10.1016/j.indmarman.2004.09.013

Sekaran, U. (1992). Research methods for business : a skill-building approach (2nd ed.). Wiley.

Shaouf, A., Lü, K., \& Li, X. (2016). The effect of web advertising visual design on online purchase intention: An examination across gender. Computers in Human Behavior, 60, 622-634. https://dx.doi.org/10.1016/j.chb.2016.02.090

Shneor, R., \& Efrat, K. (2014). Analyzing the Impact of Culture on Average Time Spent on Social Networking Sites. Journal of Promotion Management, 20(4), 413-435. http://dx.doi.org/10.1080/10496491.2014.930281

Szajna, B. (1996). Empirical evaluation of the revised technology acceptance model. Management Science, 42(1), 85-92. https://dx.doi.org/10.1287/mnsc.42.1.85

Thatcher, J. B., Stepina, L. P., Srite, M., \& Liu, Y. (2003). Culture, overload and personal innovativeness with information technology: Extending the nomological net. Journal of Computer Information Systems, 44(1), 74-81.

van Raaij, E. M., \& Schepers, J. J. L. (2008). The acceptance and use of a virtual learning environment in China. Computers \& Education, 50(3), 838-852. https://dx.doi.org/10.1016/j.compedu.2006.09.001

Venkatesh, V. (2000). Determinants of Perceived Ease of Use: Integrating Control, Intrinsic Motivation, and Emotion into the Technology Acceptance Model. Information Systems Research, 11(4), 342-365. https://doi.org/10.1287/ isre.11.4.342.11872

Venkatesh, V., \& Bala, H. (2008). Technology Acceptance Model 3 and a Research Agenda on Interventions. Decision Sciences, 39(2), 273-315.

Venkatesh, V., \& Davis, F. D. (1996). A model of the antecedents of perceived ease of use: Development and test. Decision sciences, 27(3), 451-481. https://doi.org/10.1111/j.1540-5915.1996.tb00860.x

Venkatesh, V., \& Davis, F. D. (2000). A theoretical extension of the technology acceptance model: Four longitudinal field studies. Management science, 46(2), 186-204.

Wong, K. K.-K. (2013). Partial least squares structural equation modeling (PLS-SEM) techniques using SmartPLS. Marketing Bulletin, 24(1), 1-32.

WorldBank. (2016). Sri Lanka. Retrieved November 10, 2016, from http://data.worldbank.org/country/sri-lanka

\section{Copyrights}

Copyright for this article is retained by the author(s), with first publication rights granted to the journal.

This is an open-access article distributed under the terms and conditions of the Creative Commons Attribution license (http://creativecommons.org/licenses/by/4.0/). 